\title{
Understaffing and the real cost: A burning issue
}

\section{Maskey SP}

Sandesh P Maskey, Lecturer; Burns, Plastic and Reconstructive Surgery Department, Kathmandu Medical College Teaching Hospital, Kathmandu, Nepal.

ome of the burn cases, acid attack cases on two school going girls to be precise, have caught the media attention and public sympathy in the recent past. These two cases add to some 50,000 annual cases of burn in Nepal'.

The Nepal Burn Society organized a Burn Awareness Program in 2014. Most of the burn surgeons from Kathmandu were present for the meeting of the organizing committee. One of the presentations was titled "Existing Problems and Limitations in Burns in Nepal". In the discussions we found out that not a single burn care facility in public hospitals irrespective of the number of beds was staffed by more than one nurse in the night shift.

Patients with major burns are some of the most critically ill patients in any hospital. So does understaffing significantly change outcome in Nepal?

In a retrospective observational study published in The New England Journal of Medicine in 2011, staffing of Registered Nurses below target levels was associated with increased mortality, which reinforces the need to match staffing with patients' needs for nursing care ${ }^{2}$. Likewise, a study conducted in nine European countries has given statistical backing to claims that patients' lives may be at risk when nurses are overworked ${ }^{3}$. Each patient added to a nurse's workload increased the risk of a patient dying by seven percent. Every 10 percent increase in bachelor's degree educated nurses was associated with a seven percent fall in this risk. It offered this statistical scenario: in hospitals where nurses cared for six patients each, and 60 percent of them had bachelor's degrees, the risk of patient death was nearly a third lower than in places where nurses cared for eight patients and 30 percent had such degree ${ }^{3}$.
A question that arose was whether there were methods by which adequate staffing was reinforced or punitive measures existed for violations? An act to increase the safety of hospital patients exists in the state of Maine ${ }^{4}$. Minimum, specific and numeric direct-care registered nurse-to-patient staffing ratios by hospital unit exist. The direct-care registered nurse-to-patient ratio for a burn unit is 1:2 or fewer at all times. The direct-care registered nurse-to-patient ratio for a critical care unit is $1: 2$ or fewer at all times.

There also is enforcement against a hospital. A hospital that violates the provisions is subject to enforcement action, including suspension or revocation of license to operate as follows: For a violation of the minimum staffing ratios, a fine not to exceed $\$ 25,000$ per violation plus $\$ 10,000$ per nursing unit shift until the violation is corrected.

We should be in a position to change patient outcomes in a country where a significant number of nursing graduates remain unemployed just by addressing understaffing issues. Further, they should be adequately trained in burn management, and resources must be allocated towards this, There has been efforts from Nepal Burn Society to address this issue by training nurses and other health manpower through Essential Burn Trainings ${ }^{5}$. But given the rising incidence of burn in the country ${ }^{6}$, more effort is definitely needed. It has been 17 years since a separate Burns and Plastic Unit was ever established in a hospital of Nepal (Bir Hospital) ${ }^{1}$ and many other hospitals now do have a Burn unit or department, but most of them suffer from understaffing. Adequate staffing with quality training can boost the care received by burn patients.

\section{REFERENCES}

1. National Academy of Medical Sciences. Burn and Plastic Surgery Unit [Internet]. Kathmandu: National Academy of Medical Sciences. 2014. Available from: http://nams.org.np/Burns_and_plastic_surgery.php

2. Needleman J, Buerhaus P, Pankratz VS, Leibson CL, Stevens SR, Harris M. Nurse Staffing and Inpatient Hospital Mortality. N Engl J Med. 2011;364:1037-45. 
3. Aiken LH, Sloane DM, Bruyneel L, Van den Heede K, Griffiths P, Busse R. Nurse staffing and education and hospital mortality in nine European countries: a retrospective observational study. The Lancet. 2014;383(9931):1824-30.

4. An Act To Increase the Safety of Hospital Patients.. HP1063, LD 1538, item 1, 123rd Maine State Legislature
5. Bendell R. Burn Care Training in Nepal (August 2014) [Internet]. Wales: Interburns International; 2014 Aug 18. Available from: http://interburns.org/burn-caretraining-nepal-2/

6. Rai B. A burning problem. Care for burn victims is available, but prevention would be better. Nepali Times [Internet]. 2011 Dec 2-8; Nation: [about 1 p.]. Available from: http://nepalitimes.com/news. php?id=18770\#.VTJL9NLzpdh 